\title{
From screams to dreams
}

\author{
How anesthesia revolutionized surgery
}

Asma Amir Ali, Nirushan Puvanenthirajah

Faculty Reviewer: Shelley McKellar, PhD (Department of History, Department of Surgery)

\begin{abstract}
Historically, surgery was risky and, more often than not, unsuccessful for patients. To improve surgical outcomes, medical practitioners needed to control three things: pain, bleeding, and infection. This paper will focus on how improvements with pain control contributed to changing ideas about disease and allowed for an increase in the type and quantity of surgeries performed.
\end{abstract}

\section{INTRODUCTION}

Prior to the mid-nineteenth century, surgery was not frequently performed. It was typically used as a measure of last resort due to the risk of patient hemorrhaging or infection leading to death. Operations were typically restricted to surface manipulations in part due to the sheer agony of a procedure for the patient as well as the limited ability of the surgeon to repair severely damaged internal structures. However, the advent of anesthesia changed all of that. Substances that had been used for decades to provide amusement soon found a new purpose in the fields of medicine and dentistry. ${ }^{1}$

\section{FROM ENTERTAINMENT TO MEDICINE}

The year was 1844 when Dr. Horace Wells shifted the use of nitrous oxide from entertainment (as "laughing gas frolics") to practice. A prominent American dentist, he agonised over the pain and discomfort teeth extractions caused his patients. In December 1844, Wells attended a nitrous oxide exhibition and noticed that those who inhaled nitrous oxide often stumbled and injured themselves, but showed no signs of discomfort. The following day he asked his colleague to extract a wisdom tooth from his mouth while he was under the influence of nitrous oxide gas. ${ }^{2}$ Following a painless extraction, he exclaimed that it was a "new era of teeth-pulling." This was the first application of an anesthetic in the form of nitrous oxide gas. ${ }^{2}$ The case was successful albeit controversial. Nineteenth-century physicians regarded dentists with some skepticism and it would still be a while before anesthesia use became widespread in hospitals.

\section{IMMEDIATE BENEFITS INCURRED BY ANESTHESIA}

Wells was not the only one who claimed to be the first to use an anesthetic for a medical procedure. Ether had been used in previous surgeries: Crawford Long used ether in 1842 to remove superficial neck tumours and William Morton used it as an anesthetic for a tooth extraction in $1846 .{ }^{1}$ Regardless of its origin, anesthesia found a place in hospitals. Insensibility to pain persuaded more patients to undergo necessary operations, and its use allowed surgeons valu- able time to perform more complex operations.

Before the use of anesthesia, surgeons operated on screaming, anguished patients, which took a toll on both surgeons and patients. Amputations were excruciating since the surgeon had to cut through skin and muscle with a large knife until the bone was exposed enough to saw through. Surgeons learned to complete amputations quickly and cleanly, not only to limit pain but also to prevent the spread of infection. ${ }^{3}$ Thus, anesthesia brought "pleasure from the knowledge that he (the surgeon) inflicts no pain." 4 The time and effort that went into dealing with a tormented patient could now be expended in the more technical aspects of the operation. It allowed the surgeon to perform a less rushed operation, to move through the steps of the operation more purposefully, pay closer attention to detail, and eventually perform more complex procedures. In the words of the American surgeon John Collins Warren, "who could imagine that drawing the knife over the delicate skin of the face might produce a sensation of unmixed delight!". ${ }^{4}$ The introduction of anesthesia contributed to reducing the more rudimentary and violent aspects of operations, and the practice of surgery gained greater legitimacy.

\section{ANESTHESIA'S ROLE IN DISPELLING MYTHS ABOUT DISEASE}

Cartesian dualism states that there is the mental alongside the body; the mental can exist without the body, but not vice versa. In other words, the mind and body were thought to be distinct substances that could not interact. ${ }^{5}$ This was a view held by the French philosopher Rene Descartes. ${ }^{5}$ By the mid-nineteenth century, Cartesian dualism still held a place in the medical field. However, the fact that a physical substance such as anesthesia could have such drastic effects on mental processes called into question the validity of Cartesian dualism and sparked a discussion among some intellectuals about the relationship between mind and body. ${ }^{4}$

Furthermore, in the pre-anesthetic era, there were some physicians still held the belief that pain was an essential part of disease. ${ }^{4}$ Relief from pain should thus relieve, or contribute to resolving, the individual's ailment. However, anesthesia proved that this was not the case. In doing so, a substance meant to relieve suffering during painful procedures played a role in revolutionizing medical philosophy and showing physicians that diseases could exist as their own entities outside of their symptom profiles. ${ }^{4}$ Opiates, alcohol, and other pain relievers were thought to have both analgesic and therapeutic effects. ${ }^{1}$ With this new knowledge however, physicians were forced to think about finding new ways to measure eradication of disease and to understand that treating symptoms did not necessarily also treat the underlying disease. Abolishing pain was no longer synonymous with curing a patient. 


\section{ANESTHESIA'S IMPACT ON THE QUANTITY AND TYPE OF SURGERY PERFORMED}

The introduction of anesthesia contributed to an increase in the number of operations performed in hospitals in the mid-late nineteenth century. After taking into consideration factors such as an increasing population and an increase in accidents due to the growth of railroads and industrialisation at Massachusetts General Hospital, it was observed that all types of surgery had in fact increased in occurrence. ${ }^{1}$ This rate of increase was most marked for specific subsets of the population who were more likely to receive anesthesia during an operation. These populations included the elderly, women, and amputees. ${ }^{4}$

\section{REGARDLESS OF ITS ORIGIN, ANESTHESIA FOUND A PLACE IN HOSPITALS. INSENSIBILITY TO PAIN PERSUADED MORE PATIENTS TO UNDERGO NECESSARY OPERATIONS, AND ITS USE ALLOWED SURGEONS VALUABLE TIME TO PERFORM MORE COMPLEX OPERATIONS.}

In the post-anesthesia period, patients were also requesting more operations. Nineteenth-century surgeons suspected that these were patients who had been putting treatment off for a long time or were chronically ill. ${ }^{4}$ The idea of a pain-free surgery likely made the hospital experience less frightening for the patient and increased demand for surgical procedures. However, it took surgeons some time to realize that anesthesia allowed them to be more meticulous with their procedures. ${ }^{3}$ As a result, while the operations were now pain-free, it was unlikely that surgery in the immediate post-anesthetic period was substantially more effective than during the pre-anesthetic period.

Anesthesia, however, allowed physicians to perform more experimental surgeries than they did previously. Experimental surgeries regarding palate, lip, and vaginal fistula repair increased 1.5 fold following the discovery of ether. ${ }^{4}$ Dr. George Hayward, a pioneer of reconstructive pelvic surgery, attributed his own increased experimentation rates of vesico-vaginal fistula repairs to ether. ${ }^{6}$ Furthermore, a class of patients deemed too ill to receive any surgical treatment - emergency and acute injury cases - were being operated on at four times the rate than in the pre-anesthetic period. ${ }^{6}$

\section{CONCLUSION}

The introduction of anesthesia produced an environment that was more conducive to purposeful operations. More patients were willing to undergo an operation if pain was controlled. Anesthesia shaped ideas about disease by sparking a discussion about the interaction between mind and body and teasing apart treating pain from treating disease. The use of anesthesia allowed surgeons time to perform more complex operations, paving the way for innovative techniques. In this way, a compound formerly used for entertainment revolutionized the field of surgery.

\section{REFERENCES}

1. Thatcher V. History of Anesthesia with Emphasis on the Nurse Specialist. Garland Publishing Press. 1984.

2. Jacobson PH. Horace Wells: Discoverer of Anesthesia. Anesth Prog. 1995 42: 72-75

3. Gawande A. Two Hundred Years of Surgery. The New England Journal of Medicine. 2012 366:1716-23.

4. Pernick M. A Calculus of Suffering: Pain, Professionalism, and Anesthesia in Nineteenth-Century America. Columbia University Press. 1985.

5. Rene Descartes: The Mind-Body Distinction. [Internet]. U.S.A: Internet Encyclopedia of Philosophy; 1995. [cited 2016 Dec 20]. Available from: http://www.iep.utm.edu/descmind/\#H4.

6. Surgical reports, and miscellaneous papers on medical subjects. [Internet]. Boston, Phillipis, Sampson and company. 1885. [cited 2016 Dec 20]. Available from: https://archive.org/details/surgicalreportsmoohayw.

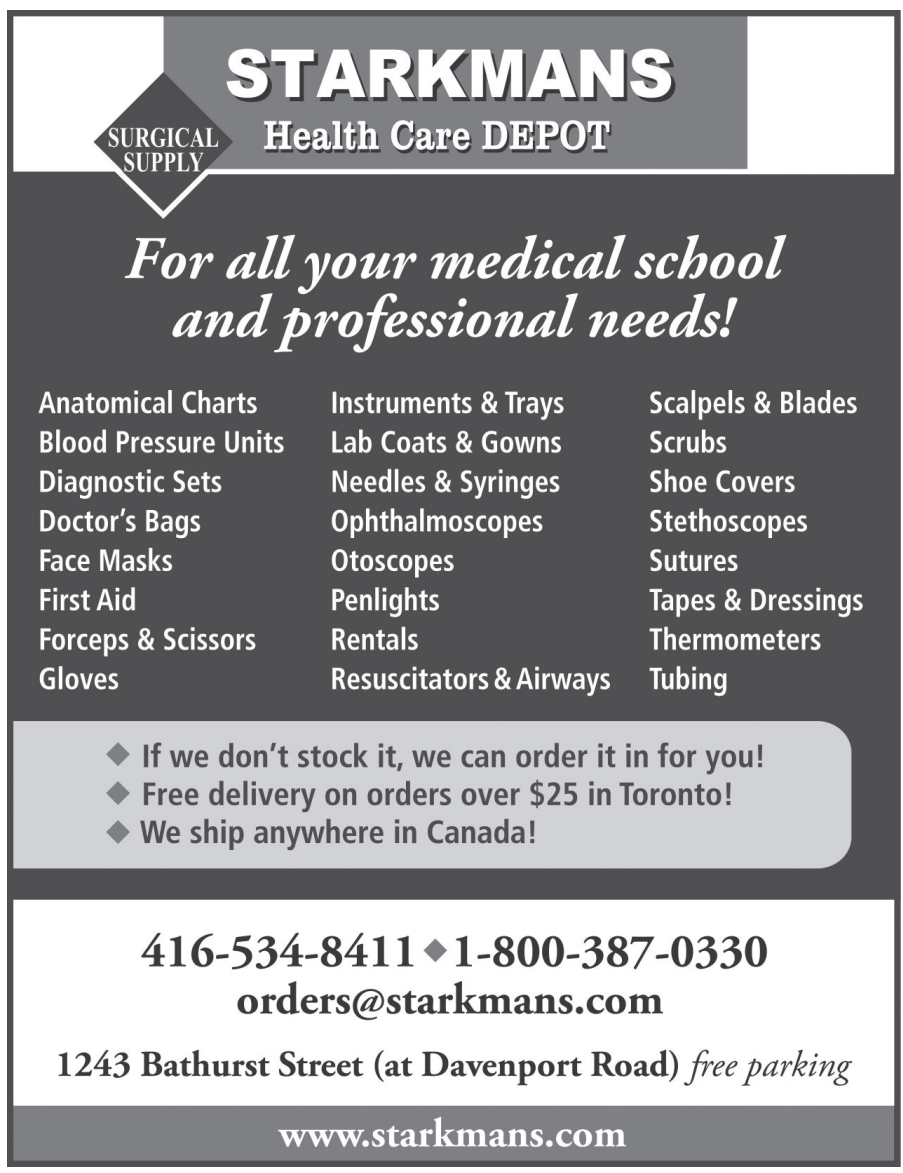

